\title{
Mice carrying paternal knockout of imprinted Grb10 do not
}

\section{show compulsive behaviours}

\author{
Kira DA Rienecker ${ }^{1, *}$, Alexander T Chavasse, Kim Moorwood ${ }^{2}$, Andrew Ward ${ }^{2}$, Trevor \\ Humby ${ }^{4} \&$ Anthony R Isles ${ }^{1, \S}$
}

${ }^{1}$ MRC Centre for Neuropsychiatric Genetics and Genomics, Neuroscience and Mental Health Research Institute, School of Medicine, Cardiff University, Hadyn Ellis Building, Maindy Road, Cardiff, UK

${ }^{2}$ Department of Biology and Biochemistry, University of Bath, Building 4 South, Bath, BA2 7AY, UK

${ }^{4}$ School of Psychology, Cardiff University, Tower Building, Park Place, Cardiff, UK ${ }^{\S}$ Corresponding author ARI, Email: IslesAR1@cardiff.ac.uk

\begin{abstract}
Mice lacking paternal expression of imprinted Grb10 show a number of social behaviour deficits, including an enhanced allogrooming phenotype. However, this could also index compulsive behaviour, and the increased whisker barbering seen in $\mathrm{Grb} 10^{+/ \mathrm{p}}$ mice has been suggested to be indicative of a trichotillomania-type behaviour. Here we test whether compulsive behaviour is a more general phenotype in $\mathrm{Grb} 10^{+/ p}$ mice by examining marble burying at three different adult ages (2, 6 and 10 months). We also examined the mice for potentially confounding anxiety phenotypes using the elevated plus maze (EPM). Grb10 $10^{+/ p}$ mice showed no difference from wild-type littermate controls on any measure in the marble burying test at any age. There was no difference in standard anxiety measures either, although $\mathrm{Grb} \mathrm{O}^{\mathrm{t} / \mathrm{p}}$ mice displayed more risk-taking behaviours on the EPM than wild-type mice. These data suggest that $\mathrm{Grb} 10^{+/ p}$ mice are not generally more compulsive, and that the enhanced allogrooming is probably indicative of altered social behaviour. Furthermore, the altered behaviours seen on the EPM adds to other published findings suggesting that Grb10, and imprinted genes more generally, have a role in mediating risk-taking behaviour.
\end{abstract}




\section{INTRODUCTION}

Imprinted genes, defined by their discrete parent-of-origin monoallelic expression based on epigenetic markers established in the germline (Bartolomei \& Ferguson-Smith, 2011), are highly expressed in the brain and are linked to behaviour. In particular, paternal expression of imprinted Grb10 is prominent in monoaminergic regions of the midbrain and is linked to social stability, impulsivity, and risk taking behaviours (Dent et al., 2018; Dent \& Isles, 2014; Garfield et al., 2011; Rienecker, Chavasse, Moorwood, Ward, \& Isles, 2019). However, many behaviourally and neurobiologically separable constructs have overlapping assessments and manifestation (Isles, Winstanley, \& Humby, 2019; Lopez-Guzman, Konova, \& Glimcher, 2018; Robbins, Gillan, Smith, de Wit, \& Ersche, 2012). Grb10 paternal knockout mice $\left(\mathrm{Grb10^{+/p }}\right)$ mice have an enhanced allogrooming phenotype (Garfield et al., 2011), which has been inferred to indicate social dominance (Strozik \& Festing, 1981; Wang, Kessels, \& Hu, 2014; Wang et al., 2011), but could also index compulsive behaviour (Curley, 2011; Haig \& Úbeda, 2011). Altered grooming behaviours are often used to model compulsivity in mice, as features such as a focused affected area and onset during puberty have compelling similarities to trichotillomania (compulsive hair plucking) (Dufour \& Garner, 2010; Kurien, Gross, \& Scofield, 2005). Genetic knockout models of compulsivity have linked facial over-grooming and anxiety phenotypes to monoaminergic dysregulation in the cortex (where Grb10 is not expressed) and striatum (where Grb10 is expressed, in monoaminergic neurons) (Garfield et al., 2011; Wood, LaPalombara, \& Ahmari, 2018). Likewise, monoaminergic neurotransmitter systems where Grb10 is expressed are implicated in the pathophysiology of obsessive compulsive disorder (OCD), an anxiety disorder characterized by compulsive behaviour and obsessive thinking (Albelda \& Joel, 2012). Nevertheless, compulsivity has not been explicitly assayed in Grb10 $10^{+/ p}$ mice.

Here, we set out to specifically assay general compulsive behaviour in the $\mathrm{Grb} 10^{+/ p}$ mouse (Cowley et al., 2014; Garfield et al., 2011). Compulsivity leads to maladaptive perseverance of actions inappropriate to the situation or overall goal (Robbins et al., 2012). The marble burying test (MBT) has good face validity for repetitive and compulsive behaviour, and detects differences between treatment conditions known to manipulate relevant neurotransmitter systems (Albelda \& Joel, 2012). This task must be coupled with measures of anxiety, as alone the MBT cannot differentiate between anxious and compulsive behaviours (Albelda \& Joel, 2012; Ichimaru, Egawa, \& Sawa, 1995). Therefore, we included the Elevated Plus Maze (EPM), a widely employed test of anxiety (Frye, Petralia, \& Rhodes, 2000; Pellow, Chopin, File, \& Briley, 1985; Walf \& Frye, 2007). Our previous observations of Grb10 $10^{+/ p}$ colonies show barbering emerges with age (Rienecker et al., 2019). Therefore, our experimental design incorporated age (at 2, 6, and 10 months) to assess whether any potential compulsivity 
phenotype varied by age. Overall, we found no evidence to support a compulsivity or anxiety phenotype in our $\mathrm{Grb} 10^{+/ p}$ mice, but data from auxiliary EPM measures supports previous findings indicate that mice lacking expression of paternal Grb10 are more willing to take risks.

\section{MATERIALS AND METHODS}

\section{Subjects}

Grb10 heterozygous knockout mice on a B6CBAF1/J background were created using a LacZ:neomycin gene-trap cassette interrupting exon 7 as previously described in Garfield et al (2011). The colony was derived via embryo transfer from a colony in Bath and breeding stock was maintained with either a B6CBA F1/crl line from Charles River (C57BL/6J:CBA/CaCrl F1 mice, the first generation progeny of a cross between female C57BL/6J and male CBA/CaCrl mice) or with an in house mixed B6CBA F1/crl x B6CBA F1/J background. Experimental animals (F2) were generated by crossing heterozygous $\mathrm{Grb}_{10} \mathrm{O}^{+-}$ males with wildtype (WT) females in order to generate litters of WT and Grb10 $0^{+/ p}$ pups. The study used three separate groups of male WT and $\operatorname{Grb} 10^{+/ p}$ mice $(2,6$, and 10 months old at the start of testing, Fig. 1) in a cross-sectional design. Mice progressed through social hierarchy tests (Rienecker et al., 2019) before the marble burying test, followed by the EPM.

Animals were weaned and housed as previously described (Rienecker et al., 2019). All groups of mice were housed in environmentally enriched cages (cardboard tubes, shred-mats, chew sticks) of 1-5 adult mice per cage. Cages were kept in a temperature and humidity-controlled vivarium $\left(21 \pm 2^{\circ} \mathrm{C}\right.$ and $50 \pm 10 \%$ respectively) with a 12-hour light-dark cycle (lights on at 7:00 hours, lights off at 19:00 hours). All mice had ad libitum access to standard rodent laboratory chow and water. Cages were cleaned and changed once a week at a regular time and day of the week for minimal disruption. All procedures were conducted in accordance with the requirements of the UK Animals (Scientific Procedures) Act 1986, under the remit of Home office license number 30/3375 with ethical approval at Cardiff University.

\section{Behavioural Procedures}

All experiments were carried out in a quiet room with one overhead light (15 lux), and behaviour was analysed using Ethovision video-tracking software (V3.0.15, Noldus Information Technology, Netherlands), via a camera placed centrally over each piece of apparatus. We used a set of quantitative descriptors about the movement and location of subjects, determined by the location of the greater body-proportion of subjects (12 frames/s). We calibrated tracking using non-experimental mice of the same body size and coat colour as experimental subjects. For each experiment, we designated appropriate virtual zones related 
to the apparatus and tracked parameters such as distance moved, time spent/zone, zone entries, velocity, and latency to enter a zone. One cage of four mice was carried into the testing room at a time, and remained until all cage mates had individually completed the task. Between cages in the marble burying task, 1/3 of the sawdust was removed and replaced with fresh material. We cleaned marbles and the EPM apparatus with $70 \%$ alcohol solution between each trial. Mice were handled as little as possible up until one week prior to the start of behavioural testing; then the researcher who would perform the behavioural tests handled the mice daily for 5 days, recording weight and barbering status.

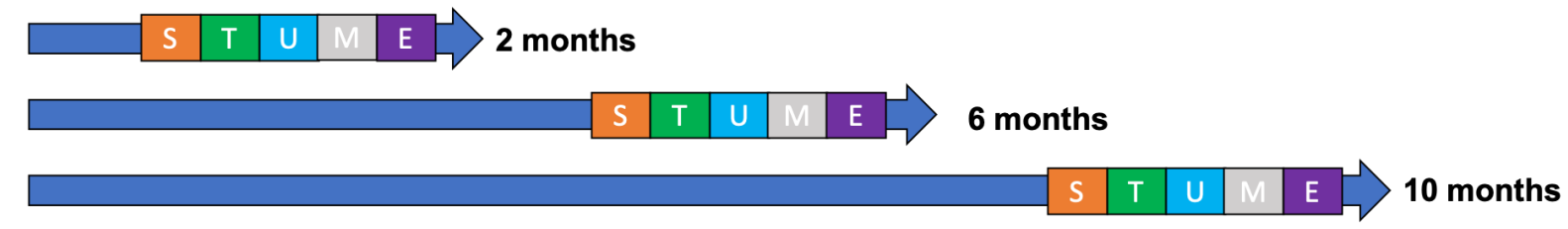

Figure 1. Schematic outlining the order of testing. Three cohorts, aged 2, 6, and 10 months were tested for stranger-encounter tube test $(S)$, social-encounter tube test $(T)$, urine marking test (U; males only), marble burying test (M), and EPM (E). Testing ended at the nominal age of the cohort and was confined to a 4 week period to prevent overlap between cohorts. Only marble burying and EPM are reported in this paper. Results from the remaining tests are reported in Rienecker et al 2019 where a version of this figure appears.

\section{Marble Burying Task (MBT)}

The MBT was conducted using previously published methods (Doe et al., 2009). Mice were placed in an arena $(40 \times 24 \times 11, \mathrm{I} \times \mathrm{w} \times \mathrm{h}$ in $\mathrm{cm})$ three-quarters filled with levelled sawdust and covered by a Perspex lid with narrow gaps on either $24 \mathrm{~cm}$ end of the box. Eight red marbles $(10 \mathrm{~mm}$ diameter) were placed in a set pattern of three rows $(2 \times 3$ marbles and a centre row of 2 marbles) in one half of the arena ("Marbles Zone"). To begin the trial, mice were placed in the "Start Zone" and allowed to freely explore the arena. Mice were recorded in the arena for 30 minutes with number of marbles displaced, half buried, and buried recorded manually every 5 minutes, and an overall total for the session was determined. Digging and grooming times were manually scored throughout the trial. Following the trial, the sawdust was turned over and fresh marbles were placed in the "Marbles Zone". The main measures of the MBT were "marbles buried", "marbles half-buried", "marbles displaced", "velocity", "total time digging", "percent time in 'start' zone", "percent time in "marbles' zone", "transitions", "total time digging", and "total time grooming".

\section{Elevated Plus Maze (EPM)}


The EPM was conducted to control for confounding effects of anxiety on the marble burying test. The maze consisted of two bisecting white arms $(43 \mathrm{~cm} \times 8 \mathrm{~cm}, \mathrm{I} \times \mathrm{w})$ at right angles to each other, was made of white Perspex, and was fixed to a stand $45 \mathrm{~cm}$ high. Opposing pairs of arms were designated "Closed arms" (with $17 \mathrm{~cm}$ high walls) and "Open arms" (without walls). All arms opened onto a centre square of $8 \mathrm{~cm}$ x $8 \mathrm{~cm}$, designated the "Middle Zone". To begin the 5-minute trial, a mouse was placed in a closed arm and allowed to freely explore. The Ethovision detection system recorded movement, while time for grooming, stretch-attend, and head dips over the edge were scored manually. The main measures are "entries to the open arm", and "percent time in open arms". These were reported in Supplementary Information for Rienecker et al., 2019. EPM measures reported here include "total entries", "entries to closed arms", "entries to middle", "velocity", "duration in stretch-attend", and "duration in head dipping behaviour".

\section{Statistics}

All statistical analyses were carried out using SPSS 25.0 for windows (IMP Corp., USA). Prior to analysis, the data were screened for outliers, Shapiro-Wilk's test was used to assess the normality of the data, and the spread of data in histograms and the shape of the residuals (RES) in Q-Q plots were examined. Outliers were further identified as trials with studentized residuals (SREs) more extreme than \pm 3 SD. Analyses were conducted first with outliers included, and results were compared to analyses with outliers excluded. Ethovision measures in the MBT and EPM tasks were analysed using a two-way ANOVA, with between-subjects independent variables GENOTYPE and AGE (2, 6, and 10 months old). Manually scored behaviours from the MBT (marbles displaced, half-buried, and totally buried) were analysed by two-way mixed ANOVA with between-subject factor GENOTYPE and within-subject factor TIME (5 minute intervals for 30 minutes). Statistical significance underwent False Discovery Rate (FDR) corrections using the Benjamini-Liu (BL) method (Y Benjamini \& Liu, 1999; Yoav Benjamini, Drai, Elmer, Kafkafi, \& Golani, 2001). FDR corrections were performed on all reported analyses belonging to one task (i.e., "marble burying task" or "EPM"), and were separate between different tasks. Graphs report descriptive means \pm standard error of the descriptive mean, unless otherwise stated. Data in main effects analyses are presented as estimated marginal mean \pm standard error of the estimated marginal mean, unless otherwise stated. 


\section{RESULTS}

\section{$\mathrm{Grb10}^{+/ \mathrm{p}}$ mice show no differences in marble burying}

A summary of the subjects assessed in the MBT at each age can be found in Table 1. For mice 2 months of age, there was no statistically significant difference between $\mathrm{Grb}^{+/ / p}$ and WT mice for marbles buried (ANOVA, interaction between TIME and GENOTYPE on marbles buried $F_{3.538,159.216}=0.507, p=0.708$, partial $\eta^{2}=0.011, \varepsilon=0.708$; main effect of GENOTYPE $F_{1,45}=0.050, p=0.823$, partial $\eta^{2}=0.001$; Figure $\left.2 A\right)$. There was also no significant difference between genotypes in marbles buried at 6 (ANOVA, main effect of GENOTYPE $F_{1,45}=1.870$, $p=0.178$, partial $\eta^{2}=0.040$; Figure $2 B$ ) or 10 months (main effect of GENOTYPE on marbles buried $F_{1,48}=1.692, p=0.200$, partial $\eta^{2}=0.034$; Figure $2 C$ ). The assumption of homogeneity of covariance was violated at 6 and 10 months, so we did not interpret the interaction between TIME and GENOTYPE for these ages.

When outliers were removed, WT and $G r b 10^{+/ p}$ marble burying profiles differed (ANOVA, interaction between TIME and GENOTYPE $F_{2.426,101.882}=2.965, p=0.046$, partial $\eta^{2}=0.066$; simple main effect of GENOTYPE at 15 minutes, $F_{1,42}=5.275, p=0.027$, partial $\eta^{2}=0.112$ ). For wildtype trials, the number of marbles buried increased statistically significantly in all pairwise comparisons except from 20 to 30 and 25 to 30 minutes. For $G r b 10^{+/ p}$ trials, the number of marbles buried increased between 5 minutes and all other time bins, but not between any other pairwise comparisons.

Table 1: Marble Burying Trials included in Analysis

\begin{tabular}{|l|l|l|}
\hline Genotype & Age & $\mathbf{N}$ \\
\hline WT & 2 months & 24 \\
\cline { 2 - 3 } & 6 months & 24 \\
\cline { 2 - 3 } & 10 months & 29 \\
\hline \multirow{3}{*}{ rb10 $^{+/ p}$} & 2 months & 23 \\
\cline { 2 - 3 } & 6 months & 23 \\
\cline { 2 - 3 } & 10 months & 21 \\
\hline
\end{tabular}



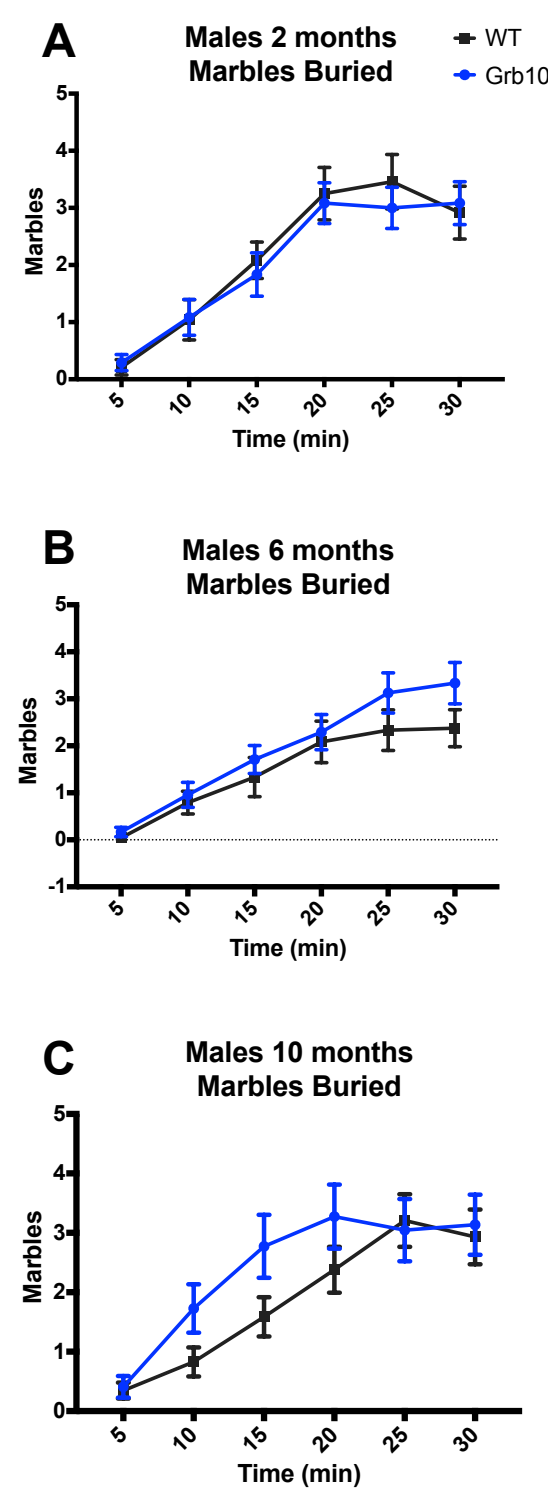

Figure 2 Marble burying behaviour.

Marbles buried by $\mathbf{A}$. male mice 2 months of age. B. male mice 6 months of age, and C. male mice 10 months of age. There was no significant effect of GENOTYPE at any age. Data are mean marbles buried with the standard error of the mean. 
For marbles half-buried or displaced, there was no significant interaction between GENOTYPE and TIME, nor main effect of GENOTYPE at any age. For marbles displaced at 6 and 10 months of age, the assumption of homogeneity of co-variances was violated and the interaction term could not be interpreted. Overall, with all data included, there were no significant interactions between GENOTYPE and TIME, nor significant main effects of GENOTYPE for marbles buried, half-buried, or displaced. We concluded there was no difference in marble burying behaviour between $\mathrm{Grb}_{10} 0^{+/ p}$ and wildtype mice.

In addition to number of marbles buried, we also recorded "velocity", "total time digging", "total time grooming", "percent time in 'start' zone" and "percent time in "marbles' zone", and "transitions". There was no significant interaction between GENOTYPE and AGE for any measure analysed with a two-way ANOVA. There were no significant main effects of GENOTYPE or AGE on velocity, "percent time spent in 'start' zone", "percent time spent in 'marbles zone", or on transitions made between zones (See Supplemental Table S1).

There was no significant main effect of GENOTYPE on "time spent digging", but there was a significant main effect of AGE: mice 2 months and 6 months of age both spent more time digging than mice 10 months of age, but there was no significant difference between mice 2 months and 6 months of age (Supplemental Figure S1). This survived FDR correction. "Time grooming" was analysed separately for each age bin, because it violated the assumption of homogeneity of error variances in the two-way ANOVA. Additionally, time grooming was analysed using a Mann-Whitney $U$ test because it violated the assumption of normality for all but one cell of the design. There was no significant difference between genotype groups in "time spent grooming" at any age bin.

Twenty one identified outliers were removed from the data set in a separate analysis to determine their impact on the statistical results. No genotype differences were revealed. Therefore, both with all data included and with outliers excluded, there were no genotype differences among the Ethovision measures during the marble burying test. This supported our conclusion that $\mathrm{Grb} 10^{+/ p}$ mice do not show differential compulsivity.

\section{Grb10 $0^{+/ p}$ mice are not more anxious on the EPM, but show auxiliary phenotypes}

The results of the marble burying test must be accompanied with a measure of anxiety to differentiate between anxious and compulsive behaviours (Albelda \& Joel, 2012; Ichimaru et al., 1995). We have previously reported our EPM findings that these $G r b 10^{+/ p}$ mice do not make more entries to the open arm or spend more total time on the open arm of the EPM compared to wildtypes after FDR correction for 63 tests (Tables 2 and 3, also reported in Rienecker et al., 2019). 
Table 2: Open Arm Entries to EPM

\begin{tabular}{|c|c|c|c|c|}
\hline Age & WT & Grb10 & F statistic & $\begin{array}{l}\text { FDR } \\
\text { (BL- p value) }\end{array}$ \\
\hline $2 \mathrm{mo}$ & $16.783 \pm 7.722$ & $19.478 \pm 6.626$ & $\begin{array}{l}F(1,44)=1.614, p \\
=0.211, \text { partial } \eta^{2} \\
=0.035\end{array}$ & $\begin{array}{l}-2.03 E-01 \\
n s\end{array}$ \\
\hline $6 \mathrm{mo}$ & $9.955 \pm 6.484$ & $15.700 \pm 6.182$ & $\begin{array}{l}F(1,40)=8.596, p \\
=0.006, \text { partial } \eta^{2} \\
=0.177\end{array}$ & $\begin{array}{l}-4.24 \mathrm{E}-03 \\
\mathrm{~ns}\end{array}$ \\
\hline $10 \mathrm{mo}$ & $11.000 \pm 6.347$ & $16.286 \pm 12.546$ & $\begin{array}{l}\text { Welch's } \\
F(1,29.300)= \\
2.995, p=0.094\end{array}$ & $\begin{array}{l}-9.03 E-02 \\
n s\end{array}$ \\
\hline
\end{tabular}

Table 3: Percent Time on EPM Open Arm

\begin{tabular}{|c|c|c|c|}
\hline Main Effect & Mean & F statistic & FDR \\
\hline GENOTYPE & $\begin{array}{l}\text { WT }(13.697 \pm 1.356 \%) \\
\text { Grb10 }^{+/ p}(19.094 \pm 1.390 \%)\end{array}$ & $\begin{array}{l}F(1,125)=7.727, p= \\
0.006, \text { partial } \eta^{2}= \\
0.058\end{array}$ & $\begin{array}{l}-4.86 \mathrm{E}-03 \\
\mathrm{~ns}\end{array}$ \\
\hline AGE & $\begin{array}{l}2 \mathrm{mo}(20.823 \pm 1.636 \%) \\
6 \mathrm{mo}(15.289 \pm 1.715 \%) \\
10 \mathrm{mo}(13.074 \pm 1.693 \%)\end{array}$ & $\begin{array}{l}F(2,125)=5.786, p= \\
0.004, \text { partial } \eta^{2}= \\
0.085\end{array}$ & $\begin{array}{l}-2.69 E-03 \\
n s\end{array}$ \\
\hline
\end{tabular}

However, while these main measures of anxiety show no differences after FDR correction, the EPM revealed auxiliary phenotypes. In addition to making more total all arm entries (Figure $3 \mathrm{~A}$ ), more closed arm entries (Figure 3B), and more middle entries (Figure 3C) than wildtypes (as reported previously), Grb10 ${ }^{+/ P}$ moved faster than wildtypes (ANOVA, main effect of GENOTYPE on "velocity" $\left(F_{1,125}=14.186, p<0.001\right.$, partial $\eta^{2}=0.102$; interaction between GENOTYPE and AGE for "velocity", $F_{2,125}=0.410, p=0.665$, partial $\eta^{2}=0.007$; Figure 4D) (Rienecker et al., 2019). Grb10 ${ }^{+/ p}$ mice had a significantly higher velocity $(4.442 \pm 0.128 \mathrm{~cm} / \mathrm{s})$ than wildtypes $(3.767 \pm 0.125 \mathrm{~cm} / \mathrm{s})$, mean difference $0.675(95 \% \mathrm{Cl} 0.320$ to 1.030$) \mathrm{cm} / \mathrm{s}, \mathrm{p}<$ 0.001 . This survived FDR correction. There was also a statistically significant main effect of AGE on "velocity" $\left(F_{2,125}=6.458, p=0.002\right.$, partial $\left.\eta^{2}=0.094\right)$, in which mice 2 months of age were significantly faster than mice 6 or 10 months of age, but this did not survive FDR correction. Overall, Grb10 $10^{+/ p}$ mice made more total entries to the EPM zones than wildtypes over the 5-minute trial by traveling faster and transitioning between closed arms through the middle zone more often. 

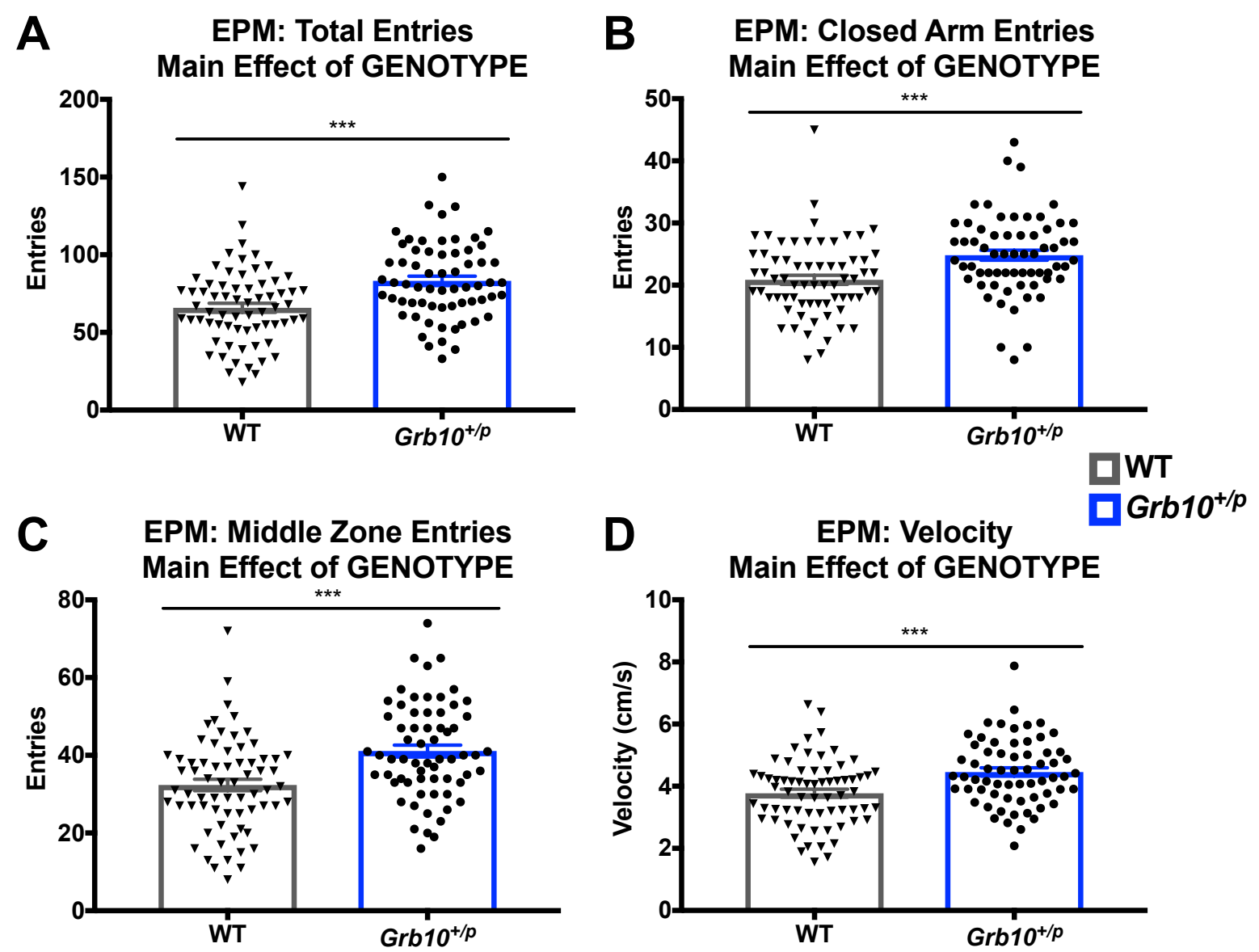

Figure 3 Main Effect of GENOTYPE for EPM Measures

A. Total entries into all zones of the EPM-There was a significant main effect of GENOTYPE $\left(F_{1,125}=17.909, p<0.001\right.$, partial $\left.\eta^{2}=0.125\right)$. Grb10 ${ }^{+/ p}$ mice made significantly more total entries (82.834 \pm 2.898 entries) than WT mice (65.698 \pm 2.828 entries). B. Closed arm entries-There was a significant main effect of GENOTYPE $\left(F_{1,125}=13.031, p<0.001\right.$, partial $\left.\eta^{2}=0.096\right)$. Grb10 $10^{+/ p}$ mice made significantly more closed arm entries $(24.741 \pm$ 0.764 entries) than WT mice (20.847 \pm 0.746 entries). C. Middle zone entries-There was a significant main effect of GENOTYPE $\left(F_{1,125}=18.166, p<0.001\right.$, partial $\left.\eta^{2}=0.127\right)$. Grb10 $1 / p$ mice made significantly more middle zone entries (40.939 \pm 1.455 entries) than WT mice (32.272 \pm 1.420 entries). D. Velocity-There was a significant main effect of GENOTYPE. Grb10 $1 / p$ mice moved faster than WT mice (statistics in text). Data have been collapsed across $\operatorname{AGE}(2,6$, and 10 months) to show the significant main effects of GENOTYPE which survived FDR correction. ${ }^{* *} p<0.001$, FDR Corrected 


\section{Grb10 ${ }^{+/ p}$ mice show a difference in risk taking but not risk assessment on the EPM}

Stretch-attend duration on the EPM is a measure of risk assessment, while head-dipping can be interpreted as a risk-taking behaviour. The expectation is that an anxious or risk-averse mouse will spend less total time in head dipping behaviour (Rodgers, Perrault, Sanger, \& Griebel, 2002; Toledo-Rodriguez \& Sandi, 2011). There was a significant difference in "stretch-attend duration" between $\mathrm{Grb}_{10}{ }^{+/ p}$ and WT animals, but this did not survive FDR correction (ANOVA, interaction between GENOTYPE and AGE, $F_{2,125}=2.820, p=0.063$, partial $\eta^{2}=0.043$; main effect of GENOTYPE on "stretch-attend duration" $F_{1,125}=4.532, p=$ 0.035 , partial $\left.\eta^{2}=0.035\right)$. There was also a significant difference in "stretch-attend duration" by age, but this also did not survive FDR correction (ANOVA, main effect of AGE on "stretchattend duration" $F_{2,125}=4.162, p=0.018$, partial $\eta^{2}=0.062$ ).

Grb10 ${ }^{+/ p}$ mice spent significantly more time in "head dip duration" than WTs (ANOVA, interaction between GENOTYPE and AGE, $F_{2,125}=2.181, p=0.117$, partial $\eta^{2}=0.034$; main effect of GENOTYPE on "head dip duration" $F_{1,125}=14.540, p<0.001$, partial $\eta^{2}=0.002$; Figure 4B). There was no statistically significant main effect of $A G E\left(F_{2,125}=0.113, p=0.875\right.$, partial $\eta^{2}=0.002$; Figure $\left.4 A\right)$. Grb $10^{+/ p}$ mice overall spent significantly more time $(48.203 \pm$ $2.555 \mathrm{~s})$ than wildtypes $(34.588 \pm 2.494 \mathrm{~s})$ in head dip behaviour, mean difference 13.615 $(95 \% \mathrm{Cl} 6.549$ to 20.682$) \mathrm{s}, \mathrm{p}<0.001$. This survived FDR correction. When outliers were removed from the analysis, the data necessitated analysis by one-way ANOVA. Under this analysis, there was still a significant genotype difference in total head dip duration at 6 months, but not at 2 months or 10 months. 
A
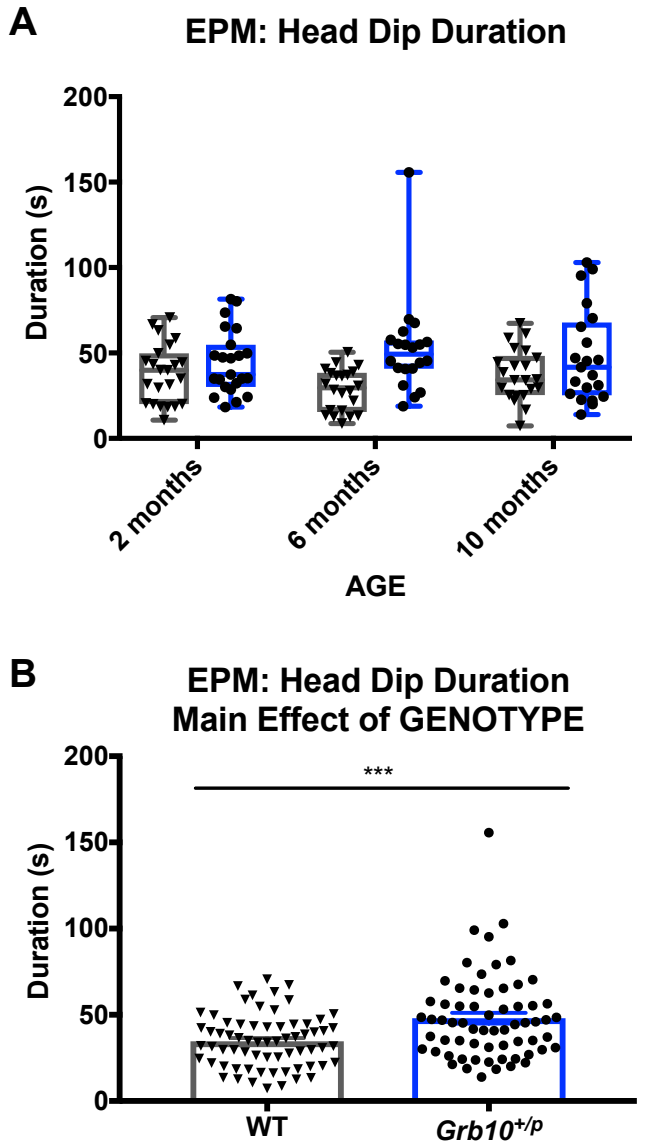

Figure 4 Head Dip Duration and Main Effect of GENOTYPE

A: Box and whisker plots displaying all data points for head dip duration in WT and Grb10 $10^{+/ p}$ mice in three age groups, with max, min, and median. The interaction between GENOTYPE and AGE was not significant.

B: Bar chart of the main effect of GENOTYPE for head dip duration with all data points displayed collapsed across AGE. There was a significant main effect of GENOTYPE. Grb10 ${ }^{+/ p}$ mice spent significantly more time in head dip behaviour on the EPM. Error bars display SEM.

\section{DISCUSSION}

We have previously reported that $\mathrm{Grb} 10^{+/ p}$ mice have altered social stability behaviour (Garfield et al., 2011; Rienecker et al., 2019), including enhanced allogrooming, or whisker barbering (Garfield et al., 2011). While allogrooming correlates with other measures of social dominance (Long, LaPorte, Paylor, \& Wynshaw-Boris, 2004; Wang et al., 2014), it is also used to model compulsivity in mice, as features such as a focused affected area and onset during puberty have compelling similarities to trichotillomania and obsessive-compulsive-like behaviour (Dufour \& Garner, 2010; Kurien et al., 2005; Wood et al., 2018). Therefore, in this work we systematically assessed compulsivity in $\mathrm{Grb}^{\mathrm{N}} \mathrm{O}^{+/ p}$ mice across age using the marble burying test, and included the elevated plus maze (EPM) to assay potentially confounding differences in anxiety. Grb10 $1 / p$ mice showed no evidence of abnormal compulsive behaviours, discounting this explanation of altered allogrooming behaviour. However, auxiliary measures on the EPM support previous evidence suggesting $\mathrm{Grb}_{10} 0^{+/ p}$ mice are more willing to take risk (Dent et al., 2020). 
The increased whisker barbering phenotype seen in $\mathrm{Grb}_{10} \mathrm{O}^{+/ \mathrm{p}}$ mice has been suggested to indicate an increased compulsive behavioural phenotype rather than being indicative of altered social behaviour (Curley, 2011; Haig \& Úbeda, 2011; and comment online on Garfield et al., 2011). We tested this directly, using the marble burying task (MBT), which is commonly used to assess compulsivity (Angoa-Pérez, Kane, Briggs, Francescutti, \& Kuhn, 2013; Doe et al., 2009) and detects differences between treatments, such as serotonin reuptake inhibitors, known to manipulate relevant monoaminergic systems (Albelda \& Joel, 2012; Witkin, 2008). As barbering changes over time (Rienecker et al., 2019), we measured marble burying at 2-, 6- and 10-months. We found no difference in marble burying measures in Grb10 $1 / p$ mice at any age. The lack of evidence for compulsive-type behaviour on the MBT is supported by our previous findings in the Stop-Signal Reaction Time (SSRT), task where Grb10 $10^{+/ p}$ mice show no differences in the SSRT compared to controls (Dent et al., 2018). The SSRT is generally related to 'stopping impulsivity', as the task measures the capacity to inhibit an already initiated response (Eagle et al., 2008; Oosterlaan, Logan, \& Sergeant, 1998), but a tendency towards simple stereotyped movements, as in compulsive behaviour, can impair performance on this test (Bari \& Robbins, 2013; Robbins et al., 2012). Collectively these data, coupled with the finding that $\mathrm{Grb} 10^{+/ p}$ and wild-type mice regrow barbered whiskers following social isolation (Garfield et al., 2011; Rienecker et al., 2019), indicate that the enhanced barbering associated with $\mathrm{Grb} 10^{+/ p}$ mice results not from a general compulsive behavioural phenotype, but is rather indicative of altered social behaviour.

We included the EPM in our experiment as the MBT alone cannot differentiate between compulsive and anxious behaviours (Albelda \& Joel, 2012; Ichimaru et al., 1995). No differences have been found in previous anxiety assessments of the $\mathrm{Grb} 10^{+/ p}$ mouse (Garfield, 2007; Garfield et al., 2011), but we included the elevated plus maze (EPM) to expand these anxiety assessments and provide measurements in our cross-sectional study (Frye et al., 2000; Pellow et al., 1985; Walf \& Frye, 2007). There was no difference in the main measures on the EPM (Rienecker et al., 2019). These findings matched those reported by Garfield et al for the open field and light-dark box tests of anxiety, confirming there were no generalized changes in anxiety (Garfield, 2007; Garfield et al., 2011). However, Grb10 ${ }^{+/ p}$ mice did display a robust increase in head-dipping behaviour on the open arm. In the absence of differences in anxiety measures such as time spent on, and entries into the open arm, head dipping could be regarded as a measure of risk-taking (Cruz, Frei, \& Graeff, 1994; Rodgers et al., 2002; Toledo-Rodriguez \& Sandi, 2011).

We have previously shown that $G r b 10^{+/ p}$ mice are more tolerant of risk in the delayed reinforcement task (DRT) and the predator odour risk-taking (PORT) task (Dent et al., 2018, 2020), matching theoretical predictions that imprinted genes regulate risk tolerance (Wilkins 
\& Bhattacharya, 2018). Unlike in the DRT and PORT, where risk-taking is related to a loss of opportunity and/or risk of predation while waiting for or pursuing a food reward, head dipping on the EPM is a risk related to directed exploration of an novel environment with no prior expectation of reward. Other measures on the EPM also support altered activity or novelty exploration strategies in $\mathrm{Grb} 10^{+/ p}$ mice (File, 2001). Grb10 $0^{+/ p}$ mice showed increased total arm, closed arm, and middle zone entries, as well as increased velocity compared to wildtype cage mates (entries to the open arm were not different (Rienecker et al., 2019)). This behaviour is curious because Grb10 $1 / p$ mice showed no differences in long (1-3 days) or short ( 5 min bins over $120 \mathrm{~min}$ ) duration locomotor activity assessments, nor any differences in the novel place preference (NPP) test (Dent et al., 2020). Increased zone entries and velocity in the EPM may not be explained by generally increased locomotion, nor enhanced exploration of a novel environment. Grb10 $0^{+/ p}$ mice may be displaying enhanced reactivity to handling; indeed, previous observations (Garfield, 2007, p 224) and our own note cages containing Grb10 animals demonstrate highly excitable behaviour on handling. However, by the EPM in our study, subjects had been extensively handled through a 4 week period of testing (Fig 1), and would be expected to have fully habituated, and perhaps impacted by prior novelty experience in the battery of tests (Rodgers \& Cole, 1993). Therefore, increased head dipping on the EPM supports increased risk tolerance seen in $\mathrm{Grb} 10^{+/ p}$ mice on the PORT and DRT data, and may be more related to cost-reward trade-offs than to novel exploration.

The data presented here, together with previous studies (Dent et al., 2018; Garfield et al., 2011; Rienecker et al., 2019), indicate $\mathrm{Grb10^{+/p }}$ mice do not have a generalised compulsive behavioural phenotype. Thus, altered allogrooming is not confounded by compulsivity behaviour, and instead supports altered social stability in $\mathrm{Grb} 10^{+/ p}$ mice (Rienecker et al., 2019). Additionally, head dipping duration from the EPM supports evidence from the DRT and PORT tasks which indicate paternal Grb10 normally acts to reduce risk-taking behaviour in cost-reward trade-offs. These findings suggest that risk-taking and social stability are aspects of behaviour upon which imprinted genes impact and, as predicted for risk taking (Wilkins \& Bhattacharya, 2018), one in which maternal and paternal genomes have differential interest.

\section{Funding}

This work was funded by Wellcome grant $105218 / Z / 14 / Z$. ARI is part of the MRC Centre for Neuropsychiatric Genetics and Genomics (G0801418).

\section{Competing interests}

The authors declare they have no competing interests. 


\section{REFERENCES}

Albelda, N., \& Joel, D. (2012). Current animal models of obsessive compulsive disorder: An update. Neuroscience, 211, 83-106. https://doi.org/10.1016/j.neuroscience.2011.08.070

Angoa-Pérez, M., Kane, M. J., Briggs, D. I., Francescutti, D. M., \& Kuhn, D. M. (2013). Marble Burying and Nestlet Shredding as Tests of Repetitive, Compulsive-like Behaviors in Mice. Journal of Visualized Experiments, (82), e50978. https://doi.org/10.3791/50978

Bari, A., \& Robbins, T. W. (2013). Inhibition and impulsivity: Behavioral and neural basis of response control. Progress in Neurobiology.

https://doi.org/10.1016/j.pneurobio.2013.06.005

Bartolomei, M. S., \& Ferguson-Smith, A. C. (2011). Mammalian genomic imprinting. Cold Spring Harbor Perspectives in Biology, 3(7), a002592.

https://doi.org/10.1101/cshperspect.a002592

Benjamini, Y, \& Liu, W. (1999). A distribution-free multiple test procedure that controls the false discovery rate. Tel Aviv University Department of Statistics and O.R, RP-SOR-99-3.

Benjamini, Yoav, Drai, D., Elmer, G., Kafkafi, N., \& Golani, I. (2001). Controlling the false discovery rate in behavior genetics research. Behavioural Brain Research, 125(1-2), 279-284. https://doi.org/10.1016/S0166-4328(01)00297-2

Cowley, M., Garfield, A. S., Madon-Simon, M., Charalambous, M., Clarkson, R. W., Smalley, M. J., ... Ward, A. (2014). Developmental programming mediated by complementary roles of imprinted Grb10 in mother and pup. PLoS Biology, 12(2), e1001799. https://doi.org/10.1371/journal.pbio.1001799

Cruz, A. P. M., Frei, F., \& Graeff, F. G. (1994). Ethopharmacological analysis of rat behavior on the elevated plus-maze. Pharmacology, Biochemistry and Behavior. https://doi.org/10.1016/0091-3057(94)90472-3

Curley, J. P. (2011). Is there a genomically imprinted social brain? BioEssays, 33(9), 662668. https://doi.org/10.1002/bies.201100060

Dent, C. L., Humby, T., Lewis, K., Ward, A., Fischer-Colbrie, R., Wilkinson, L. S., ... Isles, A. R. (2018). Impulsive choice in mice lacking paternal expression of Grb10 suggests intragenomic conflict in behavior. Genetics, 209(1), 233-239.

https://doi.org/10.1534/genetics.118.300898

Dent, C. L., \& Isles, A. R. (2014). Brain-expressed imprinted genes and adult behaviour: The example of Nesp and Grb10. Mammalian Genome, 25(1-2), 87-93.

Dent, C. L., Rienecker, K. D. A., Ward, A., Wilkins, J. F., Humby, T., \& Isles, A. R. (2020). Mice lacking paternal expression of imprinted Grb10 are risk-takers. BioRxiv, 962399. https://doi.org/https://doi.org/10.1101/2020.02.25.962399

Doe, C. M., Relkovic, D., Garfield, A. S., Dalley, J. W., Theobald, D. E. H., Humby, T., ... Isles, A. R. (2009). Loss of the imprinted snoRNA mbii-52 leads to increased 5htr2c preRNA editing and altered 5HT2CR-mediated behaviour. Human Molecular Genetics. https://doi.org/10.1093/hmg/ddp137

Dufour, B. D., \& Garner, J. P. (2010). An ethological analysis of barbering behavior. In Neurobiology of Grooming Behavior. https://doi.org/10.1017/CBO9780511676109.011

Eagle, D. M., Baunez, C., Hutcheson, D. M., Lehmann, O., Shah, A. P., \& Robbins, T. W. (2008). Stop-signal reaction-time task performance: Role of prefrontal cortex and subthalamic nucleus. Cerebral Cortex. https://doi.org/10.1093/cercor/bhm044

File, S. E. (2001). Factors controlling measures of anxiety and responses to novelty in the mouse. In Behavioural Brain Research. https://doi.org/10.1016/S0166-4328(01)00292-3

Frye, C. A., Petralia, S. M., \& Rhodes, M. E. (2000). Estrous cycle and sex differences in performance on anxiety tasks coincide with increases in hippocampal progesterone and 3a,5a-THP. Pharmacology Biochemistry and Behavior, 67(3), 587-596.

https://doi.org/10.1016/S0091-3057(00)00392-0

Garfield, A. S. (2007). Investigating the roles of mouse Grb10 in the regulation of growth and behaviour. University of Bath. Retrieved from https://europepmc.org/abstract/eth/442877

Garfield, A. S., Cowley, M., Smith, F. M., Moorwood, K., Stewart-Cox, J. E., Gilroy, K., ... 
Ward, A. (2011). Distinct physiological and behavioural functions for parental alleles of imprinted Grb10. Nature, 469(7331), 534-538. https://doi.org/10.1038/nature09651

Haig, D., \& Úbeda, F. (2011). Genomic imprinting: An obsession with depilatory mice. Current Biology, 21(7), R257-9. https://doi.org/10.1016/j.cub.2011.02.027

Ichimaru, Y., Egawa, T., \& Sawa, a. (1995). 5-HT1A-receptor subtype mediates the effect of fluvoxamine, a selective serotonin reuptake inhibitor, on marble-burying behavior in mice. Japanese Journal of Pharmacology, 68(1), 65-70. https://doi.org/10.1254/jjp.68.65 Isles, A. R., Winstanley, C. A., \& Humby, T. (2019). Risk taking and impulsive behaviour: fundamental discoveries, theoretical perspectives and clinical implications. Philosophical Transactions of the Royal Society of London. Series B, Biological Sciences.

https://doi.org/10.1098/rstb.2018.0128

Kurien, B. T., Gross, T., \& Scofield, R. H. (2005). Barbering in mice: A model for trichotillomania. British Medical Journal, 331(7531), 1503-1505. https://doi.org/10.1136/bmj.331.7531.1503

Long, J. M., LaPorte, P., Paylor, R., \& Wynshaw-Boris, A. (2004). Expanded characterization of the social interaction abnormalities in mice lacking Dvl1. Genes, Brain and Behavior. https://doi.org/10.1046/j.1601-183x.2003.00045.x

Lopez-Guzman, S., Konova, A. B., \& Glimcher, P. W. (2018). Computational psychiatry of impulsivity and risk: how risk and time preferences interact in health and disease. Philosophical Transactions of the Royal Society B: Biological Sciences. https://doi.org/10.1098/rstb.2018.0135

Oosterlaan, J., Logan, G. D., \& Sergeant, J. A. (1998). Response inhibition in AD/HD, CD, comorbid $A D / H D+C D$, anxious, and control children: A meta-analysis of studies with the stop task. Journal of Child Psychology and Psychiatry and Allied Disciplines.

https://doi.org/10.1017/S0021963097002072

Pellow, S., Chopin, P., File, S. E., \& Briley, M. (1985). Validation of open:closed arm entries in an elevated plus-maze as a measure of anxiety in the rat. Journal of Neuroscience Methods, 14(3), 149-167. https://doi.org/10.1016/0165-0270(85)90031-7

Rienecker, K. D. A., Chavasse, A. T., Moorwood, K., Ward, A., \& Isles, A. R. (2019). Detailed analysis of paternal knockout Grb10 mice suggests effects on stability of social behavior, rather than social dominance. Genes, Brain and Behavior.

https://doi.org/10.1111/gbb.12571

Robbins, T. W., Gillan, C. M., Smith, D. G., de Wit, S., \& Ersche, K. D. (2012). Neurocognitive endophenotypes of impulsivity and compulsivity: Towards dimensional psychiatry. Trends in Cognitive Sciences. https://doi.org/10.1016/j.tics.2011.11.009

Rodgers, R. J., \& Cole, J. C. (1993). Influence of social isolation, gender, strain, and prior novelty on plus-maze behaviour in mice. Physiology and Behavior.

https://doi.org/10.1016/0031-9384(93)90084-S

Rodgers, R. J., Perrault, G., Sanger, D. J., \& Griebel, G. (2002). Risk Assessment Behaviour: Evaluation of Utility in the Study of 5-HT-Related Drugs in the Rat Elevated Plus-Maze Test. Pharmacology Biochemistry and Behavior. https://doi.org/10.1016/s0091-3057(96)00402-9

Strozik, E., \& Festing, M. F. W. (1981). Whisker trimming in mice. Laboratory Animals, 15(4), 309-312. https://doi.org/10.1258/002367781780953040

Toledo-Rodriguez, M., \& Sandi, C. (2011). Stress during Adolescence Increases Novelty Seeking and Risk-Taking Behavior in Male and Female Rats. Frontiers in Behavioral Neuroscience. https://doi.org/10.3389/fnbeh.2011.00017

Walf, A. A., \& Frye, C. A. (2007). The use of the elevated plus maze as an assay of anxiety-related behavior in rodents. Nature Protocols, 2(2), 322-328.

https://doi.org/10.1038/nprot.2007.44

Wang, F., Kessels, H. W., \& Hu, H. (2014). The mouse that roared: Neural mechanisms of social hierarchy. Trends in Neurosciences, 37(11), 674-682. https://doi.org/10.1016/j.tins.2014.07.005

Wang, F., Zhu, J., Zhu, H., Zhang, Q., Lin, Z., \& Hu, H. (2011). Bidirectional control of social hierarchy by synaptic efficacy in medial prefrontal cortex. Science , 334(6056), 
693-697. https://doi.org/10.1126/science.1209951

Wilkins, J. F., \& Bhattacharya, T. (2018). Intragenomic conflict over bet-hedging.

Philosophical Transactions of the Royal Society B: Biological Sciences.

https://doi.org/10.1098/rstb.2018.0142

Witkin, J. M. (2008). Animal models of obsessive-compulsive disorder. Current Protocols in Neuroscience. https://doi.org/10.1002/0471142301.ns0930s45

Wood, J., LaPalombara, Z., \& Ahmari, S. E. (2018). Monoamine abnormalities in the SAPAP3 knockout model of obsessive-compulsive disorder-related behaviour.

Philosophical Transactions of the Royal Society B: Biological Sciences, 373(1742).

https://doi.org/10.1098/rstb.2017.0023 